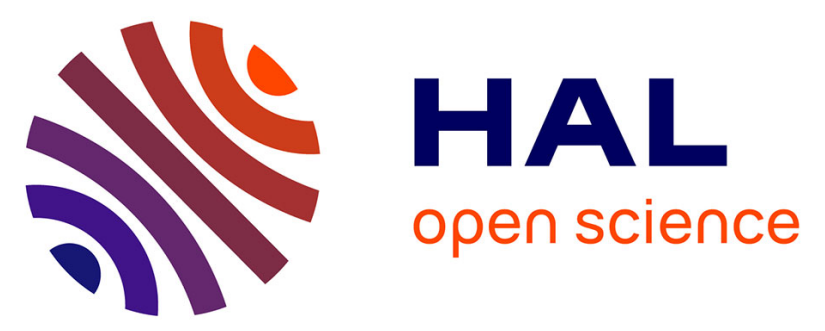

\title{
Prescribed-drug utilization and polypharmacy in a general population in Greece: association with sociodemographic, health needs, health-services utilization, and lifestyle factors
}

E. Pappa, N. Kontodimopoulos, A. A. Papadopoulos, Y. Tountas, D. Niakas

\section{To cite this version:}

E. Pappa, N. Kontodimopoulos, A. A. Papadopoulos, Y. Tountas, D. Niakas. Prescribed-drug utilization and polypharmacy in a general population in Greece: association with sociodemographic, health needs, health-services utilization, and lifestyle factors. European Journal of Clinical Pharmacology, 2010, 67 (2), pp.185-192. 10.1007/s00228-010-0940-0 . hal-00640233

\section{HAL Id: hal-00640233 \\ https://hal.science/hal-00640233}

Submitted on 11 Nov 2011

HAL is a multi-disciplinary open access archive for the deposit and dissemination of scientific research documents, whether they are published or not. The documents may come from teaching and research institutions in France or abroad, or from public or private research centers.
L'archive ouverte pluridisciplinaire HAL, est destinée au dépôt et à la diffusion de documents scientifiques de niveau recherche, publiés ou non, émanant des établissements d'enseignement et de recherche français ou étrangers, des laboratoires publics ou privés. 
Prescribed drug utilization and polypharmacy in a general population in Greece: association with socio-demographic, health needs, health services utilization and lifestyle factors

E. Pappa ${ }^{1}$ PhD, N. Kontodimopoulos ${ }^{1}$ PhD, A.A. Papadopoulos ${ }^{1,2}$ M.D., Ph.D, Y. Tountas ${ }^{1,3}$ Assoc. Professor, D. Niakas ${ }^{1}$ Assoc. Professor

${ }^{1}$ Hellenic Open University, Faculty of Social Sciences, Patras, Greece

2 “ATTIKON" University Hospital, Athens, Greece.

${ }^{3}$ Center for Health Services Research, Department of Hygiene and Epidemiology, Medical School, Athens University, Athens, Greece

\section{Corresponding Author}

Evelina Pappa

Faculty of Social Sciences, Hellenic Open University

Bouboulinas 57-59, 26222, Patras, Greece

Tel.: +302610367441

Fax: +302610367442

E-mail: evanpappa@gmail.com 


\section{Abstract}

Purpose: To analyze, in a multivariate framework, how socio-demographic, health service utilization, health needs and lifestyle risk factors influence drug utilization and polypharmacy (PP) in a general population in Greece.

Methods: The cross-sectional study took place in 2006. In total 1,005 individuals ( $>18$ years old), out of 1,388 approached (response rate $72.4 \%$ ), were interviewed by trained interviewers. Thirty seven subjects reported only OTC and they were excluded. The final sample was 968 subjects. Multivariable logistic regression and multinomial regression analyses were conducted to determine the predictors of drug use and PP at a significance level of $\mathrm{p}<0.05$.

Results: The results revealed a high rate of drug use and PP. Drug use and PP were more common among women and increased with age. Advanced age 65+ (OR: 11.6), university education (OR:2.3), visits to physician (OR: 2.2), comorbidity (OR: 6.8) or poor physical and mental health were associated with higher likelihood of using drugs. Minor (2-3 drugs) and major (4+ drugs) PP depended on comorbidity, physical health and increased age. Furthermore, visits to physicians, (O.R.:1.1), smoking (O.R.:3.0) and obesity (OR:3.8) increased the likelihood of major PP.

Conclusions: Overall, drug utilization and PP depended on health needs followed by education, utilization of health services and age. Social disparities do persist and, after adjustments for health needs and obesity, had a significant influence on PP.

Keywords: Drug use, polypharmacy, general population, socio-demographic characteristics, health needs, Greece 


\section{Introduction}

Drug utilization is the most common medical intervention used to reduce a variety of health risk factors (cardiovascular risk factors), to prevent acute events and to treat diseases. Variation in the pattern of drug utilization, large pharmaceutical consumption, polypharmacy (PP) with the drug-adverse reactions and increased trends of pharmaceutical expenditures are some of the major concerns for health care systems.

Many studies have focused on the prevalence of drug use covering several factors which may influence utilization. Gender differences have been extensively investigated as well as utilization among elderly people who are the major drug users [1-6]. Socioeconomic characteristics, health status and health risk factors are important determinants of variations in drug utilization [1,7-14]. However, few studies have investigated drug utilization in a multivariate framework involving all the abovementioned variables $[1,8,12]$.

PP surveys, on the other hand, are age-specific and focused on the elderly population. Previous studies have investigated the determinants of PP, reporting socio-demographic [15-18], medically-related [16-19] and health system factors [20] as significant predictors of PP use or the adverse effects of PP such as drug reactions and the increasing risks of hospitalization [21-23]. There is a lack of consensus on the specific number of drugs required to define PP, which has been defined as simultaneous use of more than one prescribed drug and classified as minor (2-4 drugs) and major (5+ drugs) [15], or as long-term with use of two or more drugs for at least 60 days per quarter per year [24]. Other studies define PP as 6-9 drugs and excess PP (10+ drugs) [25] or included OTC remedies [16].

In Greece, previous studies on drug utilization were very limited, population and area-specific [26-27], whereas PP has not been investigated so far. Drug consumption is very high and there is a rapid increase in pharmaceutical expenditures as a proportion of total health expenditures. According to OECD data [28], in 2006 pharmaceutical expenditures amounted to $24.8 \%$ of total health expenditures, whereas in 1997 this proportion increased to $16.2 \%$. Political measures, such as the list, to control the growth of pharmaceutical expenditure proved ineffective [29]. On this ground, it is very important to study how the drugs are used by the population, which factors affect drug utilization, taking in mind social aspects or whether drugs are being used according to health needs.

The present study was undertaken in order to cover the absence of surveys on medicine utilization and PP in Greece by investigating the prevalence of the self-reported general use of prescribed drugs and PP. Furthermore, the aim was to evaluate, in a multivariate framework, the combined effect of various factors found in previous studies such as socio- 
demographic, use of health services, health needs and health risk factors relating to lifestyle on prescription drug use and on PP in a representative sample of general population.

\section{Materials and Methods}

Study and data

The cross-sectional study took place in September 2006 and involved a sample of adults (>18 years old) residing in urban $(>2,000$ inhabitants $)$ and rural $(<2,000$ inhabitants $)$ areas of the country and each of the 13 geographical regions. According to the latest Population Census (2001), the survey population consisted of approximately 8,880,924 individuals. Non-fluent Greek speakers, institutionalized subjects and those incapable of reasoning and decision-making on their own were excluded. Participants were grouped, in proportion to the Greek population, by socio-demographic characteristics, according to a three-staged sampling methodology. In the first stage, a random sample of building blocks was selected in proportion to size. In the second stage, households were randomly selected by systematic sampling. In the third stage, an eligible participant was selected by simple random sampling in each household.

In total 1,005 willing subjects, out of 1,388 initially approached (response rate $72.4 \%$ ), were interviewed by trained interviewers. Thirty seven out of 1,005 participants reported taking only OTC drugs and they were excluded from the analysis because they represented a small group. The reported OTC drugs were analgesics, anti-inflammatory and antacids. The study was focused on the 968 participants. This health survey covered a wide range of information. The questionnaire consisted of five main parts: health-related quality of life measured by the SF-36 Health Survey, health behavior, morbidity, utilization of health services (including drug use) and socio-demographic characteristics.

\section{Measurements}

Prescribed drug utilization was measured by the question "Do you currently take some sort of medication on a daily basis?" It was explained to the participants that "currently" referred to the previous 14 days, whereas "daily basis" meant regular or continuous intake of medicines. Answers yes or no to the above question represented use or no use of the drugs respectively. Furthermore, the interviewer recorded the name of the drugs, the dosage form (tablets or injections) and the extent of consumption (e.g. the number of drugs taken). PP was defined as simultaneous use of more than one drug and classified as minor (2-3 drugs) and major (4+ drugs). All the reported drugs were classified under one of the following 
categories: antihypertensives, antithrombotics, hypolipidemics, antidiabetics, insulin, analgesics, laxatives and psychotropics.

Socio-demographic characteristics

The demographic characteristics were measured by the three categorical variables of gender, age and marital status. Education and occupation were the two variables measuring the socio-economic status of the participants. Educational level was classified into three levels: primary (reference category), secondary and university level. Occupation was recorded by asking the participants to choose the position best describing their current employment from a list including: employer, employee, retired, other (unemployed, students, and housewives, as reference category). Participants also reported their place of residence (urban/rural)

\section{Health service utilization}

The participants were asked to report the number of visits to a general physician, a specialist, a hospital out-patient clinic or if they had been admitted to hospital during the previous twelve months. Up to three visits was considered as normal use while four or more visits were thought of as high use of health services. Regarding hospitalisation, any use (admission) was contrasted to no use.

\section{Health needs factors}

Health needs were measured by the following proxy variables: self-assessed health, comorbidity and health risks. Selfassessed health was measured by the Greek version of SF-12 which has been validated in a national representative general population sample in a previous study [30]. With the SF-12 we assessed the physical and mental health of the respondents on a scale of $0-100$, with higher scores reflecting better perceived physical and mental health. Comorbidity was based on the presence or not (and the number) of chronic diseases. Respondents were asked to report whether they suffered from at least one of the following thirteen chronic diseases: diabetes mellitus type I \& II, hypertension, hyperlipideamia, heart failure, coronary ishaemic disease, irritable bowel syndrome, chronic bronchitis, asthma, osteoarthritis, Alzheimer's, depression and anxiety disorders. Chronic disease was a continuous variable ranging from 0 (no chronic disease) to 5 chronic diseases (the highest reported number).

Health risks, such as smoking and alcohol consumption, which are behaviours that stem from the individual's harmful lifestyle, which are believed to contribute to the development of illness and to the impairment of health. Participants were asked if they were smokers and they were classified as non- or daily/occasionally smokers. Information about alcohol 
consumption was based on the question "How many portions (e.g. a glass of wine) of alcoholic beverages on average do you consume per week?". Respondents were classified as consuming up to seven glasses of wine per week or consuming more. Finally, obesity is another independent variable which constitutes a contemporary disease associated with chronic diseases such as diabetes and cardiovascular disease, as well as health risks like physical inactivity and unhealthy nutrition. Obesity was assessed by the body mass index (BMI), and respondents were regarded as either normal (BMI $<25)$, overweight $(25 \leq \mathrm{BMI}<30)$ or obese $(\mathrm{BMI} \geq 30)$.

Statistical Analysis

After the selection of the factors that possibly determine drug use and PP according to the literature, a chi-square test was used to assess whether prevalence of drug utilization and PP differed across socio-demographic characteristics. Multivariable stepwise logistic regression analysis was conducted to determine the predictors of drug utilization. A logistic regression model, using forward Wald selection, was run and we used the exponentiation of B coefficient $\operatorname{Exp}(\mathrm{b})$ in order to estimate the adjusted odds ratio (OR) for each independent factor (socio-demographic, utilization of health care, health need proxies) with $95 \%$ confidence intervals. Multinomial logistic regression analysis using forward stepwise selection was further applied to analyze the impact of the independent variables on minor and major PP, with the reference category corresponding to those taking one drug. Results were considered statistically significant when $\mathrm{p}<0.05$ and all analyses were performed using SPSS v17.0.

Oral informed consent was obtained from the participants before the interview. The study was approved by the ethics committee of the Hellenic Open University.

\section{Results}

\section{Prevalence of drug use and polypharmacy}

Four hundred one respondents (i.e. $41.6 \%$ ) were drug users taking at least one drug every day. Approximately, $26 \%$ of the sample reported taking more than one drug while this proportion among drug users was $61.92 \%$. Almost $28 \%$ of the sample had made more than four visits to a physician while $11.4 \%$ reported that had been hospitalized during the previous twelve months. 
Table 1. Descriptive characteristics of health care use

Variables $\quad \mathrm{N} \quad \%$

Total

968

\section{Medication Use}

\begin{tabular}{|c|c|c|}
\hline Yes & 401 & 41.6 \\
\hline No & 564 & 58.4 \\
\hline Missing & 3 & \\
\hline Medicin & & \\
\hline 0 & 564 & 58.4 \\
\hline 1 & 153 & 15.9 \\
\hline $2-3$ & 155 & 16.1 \\
\hline $4+$ & 93 & 9.6 \\
\hline Missing & 3 & \\
\hline Number & & \\
\hline 0 & 297 & 31.6 \\
\hline $1-3$ & 385 & 41.0 \\
\hline $4+$ & 257 & 27.4 \\
\hline Hospital & & \\
\hline Yes & 109 & 11.4 \\
\hline No & 849 & 88.6 \\
\hline Missing & 10 & \\
\hline
\end{tabular}

The proportion of drug users increased with increasing age in both genders $\left(\chi^{2}\right.$-test, $\left.\mathrm{p}<0.0001\right)$ (fig. 1). Women used more medicines than men in each age group, but gender differences were statistically significant only in the older age groups of 55-64 and 65+ years old ( $\mathrm{p}<0.01)$ with women having higher likelihood of using drugs (data not shown). 


\section{Figure 1. Drug use according to gender in each age group}

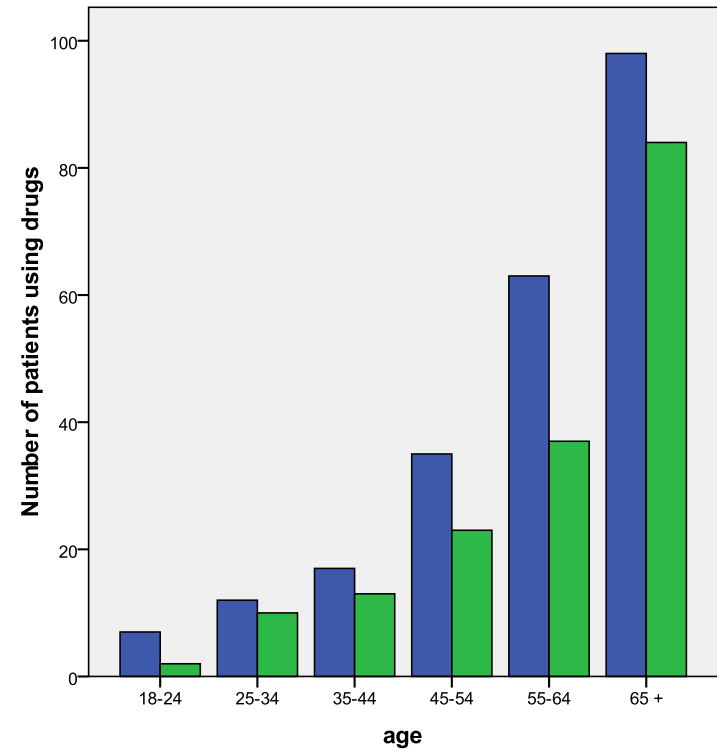

gender

$\square$ female

The number of drugs taken, also increased with increasing age $\left(\chi^{2}\right.$-test, $\left.\mathrm{p}<0.0001\right)$ (fig.2). Taking 1 or $2-3$ drugs increased with age starting from the ages between 18-24, where taking one drug was the most common case, whereas taking four or more drugs occurred from the age group of 35-44 and increased rapidly with age, which was expected and confirmed that PP is associated with older age. Regarding the reported drugs (data not shown), anti-hyperntensives were the most common taken 
Figure 2. Number of drugs taken according to population age

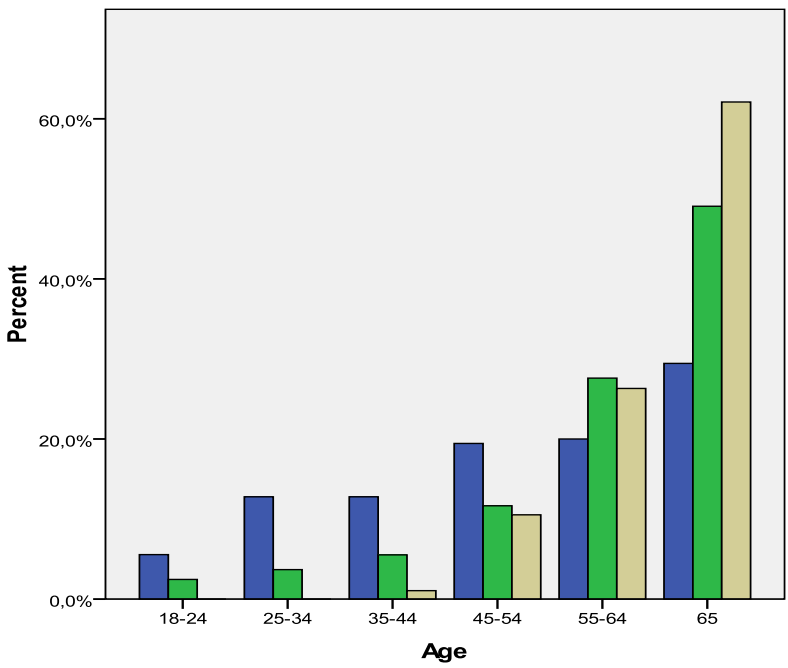

drugsnumber

${ }^{\circ}{ }^{12-3}$

Univariate analysis (table 2) showed that all the socio-demographic variables were significantly associated with drug utilization, while PP was associated only with age, marital status, education and employment status. Drug use was higher among women $\left(\chi^{2}\right.$-test, $\left.\mathrm{p}<0.01\right)$, older people $\left(\chi^{2}\right.$-test, $\left.\mathrm{p}<0.0001\right)$, married , $\left(\chi^{2}\right.$-test, $\left.\mathrm{p}<0.0001\right)$, those living in urban areas $\left(\chi^{2}\right.$-test, $\left.\mathrm{p}<0.05\right)$, those with primary education $\left(\chi^{2}\right.$-test, $\left.\mathrm{p}<0.0001\right)$ and the retired $\left(\chi^{2}\right.$-test, $\left.\mathrm{p}<0.0001\right)$, whereas older people $\left(\chi^{2}\right.$-test, $\left.\mathrm{p}<0.0001\right)$, those married $\left(\chi^{2}\right.$-test, $\left.\mathrm{p}<0.05\right)$, those with primary education $\left(\chi^{2}\right.$-test, $\left.\mathrm{p}<0.0001\right)$ and the retired $\left(\chi^{2}\right.$-test, $\left.\mathrm{p}<0.0001\right)$ were more prone to PP.

Table 2. Descriptive characteristics and socio-demographic differences in drugs utilization and polypharmacy (minor and major)

Variables Drug use $(\mathbf{n}=\mathbf{4 0 1})$

$232(57.9)$

$\mathrm{p}<0.01$

sig*

Age

\section{Polypharmacy $(n=248)$}

107 (43.1)

$141(56.9)$

NS

$2(0.8)$ 


\begin{tabular}{|c|c|c|}
\hline $25-34$ & $22(5.5)$ & $5(2.0)$ \\
\hline $35-44$ & $30(7.5)$ & $10(4.0)$ \\
\hline $45-54$ & $58(14.0)$ & $28(11.3)$ \\
\hline $55-64$ & $100(24.9)$ & $68(27.4)$ \\
\hline $65+$ & $182(45.4)$ & $135(54.4)$ \\
\hline $\operatorname{sig} *$ & $\mathrm{p}<0.001$ & $\mathrm{p}<0.001$ \\
\hline \multicolumn{3}{|c|}{ Marital status } \\
\hline Unmarried & $36(9.0)$ & $16(6.5)$ \\
\hline Married & $365(91.0)$ & $232(93.5)$ \\
\hline sig* & $\mathrm{p}<0.001$ & $\mathrm{p}<0.05$ \\
\hline \multicolumn{3}{|l|}{ Residence } \\
\hline Urban & $286(71.3)$ & 178 (71.8) \\
\hline Rural & $115(28.7)$ & $70(28.2)$ \\
\hline sig* & $\mathrm{p}<0.05$ & NS \\
\hline \multicolumn{3}{|l|}{ Education } \\
\hline Primary & $221(52.8)$ & $151(61.1)$ \\
\hline Secondary & $121(30.3)$ & $61(24.7)$ \\
\hline University & $68(17.0)$ & $35(14.2)$ \\
\hline sig* & $\mathrm{p}<0.001$ & $\mathrm{p}<0.001$ \\
\hline \multicolumn{3}{|c|}{ Employment status } \\
\hline Employers & $70(17.5)$ & $36(14.6)$ \\
\hline Employees & 49 (12.3) & $19(7.7)$ \\
\hline Retired & $176(44.0)$ & $130(52.6)$ \\
\hline Others & $105(26.3)$ & $62(25.1)$ \\
\hline sig* & $\mathrm{p}<0.001$ & $\mathrm{p}<0.001$ \\
\hline
\end{tabular}

* 2-sided significance according to chi-square test

$\mathrm{NS}=$ non significant

Drug use and polypharmacy 
Logistic regression analysis (table 3) showed that female gender was associated with greater drug utilization but the results showed statistical insignificance (O.R.:0.8, CI:0.451-1.318) after adjusting for social and health need factors. Older people had a higher likelihood of using drugs. The predicted odds of people aged $65+$ years old using drugs were almost twelve times the odds for young people aged 18-24 years old (OR: 11.6, CI:2.923-45.856). Remarkable differences in the magnitude of the odds ratio occur from the age group of 35-44, where these differences approximately were doubled or more as the age group increased. Education was associated with drug utilization, with highly educated individuals (university) being more than 2 times likely (OR: 2.3) to use at least one drug compared to those with primary education, after controlling for health needs and health services utilization. Furthermore, people who made more visits to a physician (4 times or more) during the past 12 months had a higher likelihood (OR:2.2) of taking a medicine. Regarding the need proxy variables, having at least one chronic disease was the strongest predictor with the odds ratio almost seven for being a drug user, with each increase in the number of chronic diseases. Those reporting better physical and mental health were $10 \%$ less likely to take medication $\left(\mathrm{OR}_{\mathrm{PCS}}=0.9, \mathrm{OR}_{\mathrm{MCS}}=0.9\right)$. Employment status did not give statistically significant results, whereas marital status, urbanity and lifestyle characteristics were not associated with drug utilization, and thus were excluded from the model. All the independent variables explained $69.2 \%$ of the variability of the model, implying that they were the best predictors of drug use.

Table 3. Multivariate logistic regression analysis results of drugs utilization

\begin{tabular}{llll}
\hline Variables & O.R. & $\mathbf{9 5 \%}$ CI & p-values \\
\hline Gender & 0.8 & $0.451-1.318$ & NS \\
(female) & & & \\
Age (18-24) & & & \\
$25-34$ & 0.9 & $0.313-3.008$ & NS \\
$35-44$ & 1.2 & $0.380-4.158$ & NS \\
$45-54$ & 2.4 & $0.725-8.004$ & NS \\
$55-64$ & 5.9 & $1.686-19.989$ & $<0.01$ \\
$65+$ & 11.6 & $2.923-45.856$ & $<0.001$ \\
Education (primary) & & & \\
secondary & 0.8 & $0.587-1.917$ & NS \\
\hline
\end{tabular}




\begin{tabular}{llll}
\hline university & 2.3 & $1.139-4.812$ & 0.021 \\
Employment (other) & & & \\
Employers & 1.5 & $0.713-3.131$ & NS \\
Employees & 0.7 & $0.335-1.517$ & $\mathrm{NS}$ \\
Retired & 1.0 & $0.407-2.544$ & $\mathrm{NS}$ \\
Number of visits & 2.2 & $1.088-4.258$ & $<0.001$ \\
Hospitalization (No) & 1.8 & $0.813-4.379$ & $\mathrm{NS}$ \\
Comorbidity & 6.8 & $4.193-11.034$ & $<0.001$ \\
PCS 12 & 0.9 & $0.910-0.972$ & $<0.001$ \\
MCS 12 & 0.9 & $0.937-0.987$ & $<0.001$ \\
$\mathrm{R}^{2}$ & 0.692 & & \\
\hline
\end{tabular}

PCS12 $=$ Physical Component Score, MCS12= Mental Component Score

$\mathrm{NS}=$ non significant $(\mathrm{p}>0.05)$

For categorical explanatory variables, the reference group for the calculation of the odds ratio (OR) is indicated in the parenthesis.

Multinomial logistic regression analysis (table 4) -by assessing the odds ratio for minor or major PP- showed that in the case of minor PP the only significant predictors were age, comorbidity and physical health. Advanced age increased the odds of taking 2-3 drugs by a factor of $10 \%$ (in multinomial analysis age was used as continuous variable). Having at least one chronic disease (and for each increase) the odds of using 2-3 drugs increased 2 times (OR: 2.0, CI:1.109-3.776), whereas for each unit increase in physical health (PCS-12) the odds decreased by 10\% (OR:0.9, CI:0.927-0.983). Concerning major PP, with each increase in the number of chronic diseases, the odds of using 4+ drugs were increased almost ten times (OR: 9.6, CI:2.612-35.322), while with each unit increase in physical (PCS-12) and mental (MCS-12) health, the odds of using $4+$ drugs were decreased by $10 \%$. Age was also a predictor, as with each year increase the odds of using $4+$ drugs increased by $5.9 \%$. More health care visits increased the probability of major PP by a factor of $10 \%$. Among lifestyle characteristics only smoking was significantly related to major PP with smokers being almost 3 times more likely to take $4+$ drugs. Finally, obesity (bmi $\geq 30$ ) increased the probability of major PP by a factor of 3.8. Obese individuals were almost 4 times more likely to use 4+ drugs compared to individuals with normal weight.

Table 4. Multinomial logistic regression analysis results for minor and major PP

\begin{tabular}{|c|c|c|c|c|c|c|}
\hline & \multicolumn{3}{|c|}{ Minor PP (n=155) } & \multicolumn{2}{|c|}{ Major PP (n=93) } & \\
\hline Variables & O.R. & $95 \% \mathrm{CI}$ & p-value & O.R. & 95\% C.I. & p-value \\
\hline
\end{tabular}


BMI (natural)

$\begin{array}{lllllll}\text { Obese } & 1.3 & 0.556-2.901 & \text { NS } & 3.8 & 1.196-12.145 & 0.024 \\ \text { Overweight } & 1.6 & 0.797-3.229 & \text { NS } & 2.4 & 0.852-6.930 & \text { NS } \\ \text { PCS-12 } & 0.9 & 0.927-0.983 & 0.002 & 0.9 & 0.891-0.957 & <0.001 \\ \text { MCS-12 } & 1.0 & 0.979-1.037 & \text { NS } & 0.9 & 0.928-0.996 & 0.030 \\ \text { Smoking (yes) } & 0.9 & 0.492-1.656 & \text { NS } & 3.0 & 1.190-8.061 & 0.021 \\ \mathrm{R}^{2} & 0.519 & & & & & \end{array}$

PCS12= Physical Component Score, MCS12= Mental Component Score

$\mathrm{NS}=$ non significant $(\mathrm{p}>0.05)$

For categorical explanatory variables, the reference group for the calculation of the odds ratio (OR) is indicated in the parenthesis.

\section{Discussion}

The present study was conducted with a cross-sectional design using face-to-face interviews to collect information on drug utilization and PP in a representative sample of the Greek general population. It was undertaken in order to cover the absence of studies related to drug utilization and polypharmacy in Greece. This study adds new knowledge by examining the combined effect of various variables on drug use and especially on PP. Previous studies on medicine utilization in a multivariate framework in representative general populations are few $[1,8,12]$, and as far as we know, PP has not been studied in a multivariable framework. The results revealed a high rate of drug use and PP as well. Anti-hypertensives were the most commonly taken drugs since hypertension is the most common chronic disease, its prevalence is high [31] and there is a need for daily treatment.

A key finding of this study was that social disparities in medicine use exist in the Greek general population. Education was a strong predictor, with a higher educational level increasing the likelihood of using medicines after adjustment for health need and health service factors. This finding was not in accordance with previous studies which found a weak influence of education and an inverse association with medicine use [1, 11-12]. The reduced use of medicines by less- 
educated individuals is a concern, since low education is related to poor health [32] and therefore they are more vulnerable. A crucial question is why these differences still exist and whether these differences are due to the patients or to physician/health system characteristics. The reduced use may represent under- or inappropriate treatment for the less educated and may reflect poorer communication with physicians (since education influences attitudes and knowledge) or non compliance to doctors' advice. It is therefore of great importance to acquire more knowledge about the process leading to social inequalities in drug use in order to take the appropriate measures ensuring equal treatment for all individuals. Finally, our study did not confirm findings from previous studies [16-18] about the relation between low educational level and PP.

The effect of health need, measured by morbidity and self-assessed health (i.e. physical and mental health), was significant as expected. Morbidity/comorbidity, physical and mental health were strong predictors of medicine use and PP. This is in accordance with results from previous studies $[8,12,16,25,33]$ and support findings that morbidity and selfassessed health are important determinants. It is reasonable to assume that people who rate their health as poor or using diagnosis reporting that they suffer from at least one chronic disease had a higher likelihood of using drugs or were more prone to PP in cases of severe illness or several diseases. An important viewpoint is that mental health is associated with major PP, and this is realistic since mental diseases are likely to be exposed to excess multiple drug treatment.

A large number of visits to a doctor, i.e. more than four times, within the last twelve months increased the likelihood of medicine use and major PP after adjustment for morbidity and self-assessed health. In our sample $40 \%$ of those reported visiting a doctor had made more than four visits within the last year. This high health service utilization implies an enormous cost for the health care system, which constitutes a very important issue for Greece where the pharmaceutical expenditures have increased rapidly and impose a huge burden on health care budgets.

In agreement with previous studies we found that medicine use was more common among women than men and increased with increasing age $[1,3,8,12,16]$. Multivariate analysis, after adjusting for other independent variables such as comorbidity and health service utilization, showed that gender differences were statistically insignificant. This indicates a weak effect of gender on drug use, with health need (comorbidity) and health service utilization as confounders in the association between gender and drug utilization. However, by analyzing gender differences according to age we observed that women were more likely than men to use medicines in the advanced age groups (data not shown) and the increased age-related morbidity is the most obvious explanation. PP is associated with increasing age, a finding that is common in 
previous studies and furthermore is confirmed by the fact that the majority of studies regarding PP focus the research on elderly populations

Subsequently, our analysis found that BMI affected major PP. Association between obesity and drug use was found previously $[7,16]$. It is reasonable to assume that a high bmi $(\geq 30)$ is associated with higher drug use, as obesity was thought to be a contemporary disease which threatens peoples' health and their quality of life and is correlated with poor health and many chronic diseases such as diabetes, and on the other hand chronic diseases such as diabetes, cardiovascular diseases or depression may lead to physical inactivity and rising BMI. Furthermore, the relationship between obesity, PP and higher risk of hospitalization is of great importance to be studied further. In our study we found that health risks such as smoking affected major PP, a finding that is in accordance with a previous study among old men [16], whereas results from another previous study showed greater general drug use by smokers [1]. The relation between smoking and several severe diseases like cardiovascular diseases or cancer is the obvious explanation.

There are some limitations in our study. The sampling strategy focused on households, so a specific population having a greater need and higher utilization of drugs and of PP, such as institutionalized individuals were excluded. However, this strategy was followed by the majority of the health care utilization studies. Moreover, people reporting only OTC medicines were excluded from our analysis because they constituted a small group of 37 individuals. A larger sample of OTC users would permit us to separately analyze the utilization of the two different types of medicine and compare the results. As mentioned before, daily/regular use may exclude drugs taken occasionally and this could be a possible limitation of our study. There may be an underestimation of PP as daily/regular use left out occasionally taken drugs (sleep medication, analgesics etc), but in our study the portion of PP (minor and major) amounted to almost $62 \%$ of drug users. The high rate of reported PP minimizes the risk of underestimation and contributes to the quality of the data.

\section{Methodological considerations}

One of the most important methodological issues in investigating drug utilization through questionnaires is the recall period. As suggested in a previous study [34] there is no consistency in the literature about the ideal recall period, while the prevalence of drug use is dependent on the recall period. Furthermore, another previous study [35] showed that the 
accuracy of recall of drugs taken, decreased with increasing age and the increasing number of medicines. In drug utilization studies the recall period varied from one $[7,9]$ to fourteen days $[1,8]$.

In our study we asked respondents about daily (regular) use during the "current period", which was defined as the previous fourteen days. Since this study deals with daily use there may be minor problems with recall bias, minimizing the problem of remembering the drugs taken and their exact number, As it is stated, validity of self-reported data composes a question in drug utilization studies. In this study we hypothesized that all drugs used were reported correctly by the interviewees and the high response rate (72.4) contributes to data quality and to the validity of the results. 


\section{References}

1. Eggen AE (1994). Pattern of drug use in a general population-prevalence and predicting factors: the Tomso study. Int J Epidemiol 23:1262-1272. doi: 10.1093/ije/23.6.1269

2. Del Rio C, Prada C, Alvarez J (1997). The use of mediation by the Spanish population. Pharmacoepidemiol Drug Saf 6:41-48, doi: $10.1002 /$ pds. 250

3. Eggen AE (1997). Patterns of medicine use in a general population (0-80). The influence of age, gender, diseases and place of residence on drug use in Norway. Pharmacoepidemiol Drug Saf 6:179-187, doi:10.1002/pds.258

4. Simoni M, Pedreschi M, Baldacci S et al (2000). The PO River Delta epidemiological study: use of medicines in a general population sample of north Italy. Pharmacoepidemiol Drug Saf 9:319-326, doi: 10.1002/pds.505.

5. Fernandez-Liz E, Modamio P, Catalan A et al (2007). Identifying how age and gender influence prescription drug use in a primary health care environment in Catalonia Spain. Br J Clin Epidemiol 65:407-17.

6. Sanfelix J, Palop V, Pareiro I et al (2008). Gender influence in the quantity of drugs used in primary care. Gas Sanit 22:11-9.

7. Bardel A, Wallander MA, Svardsudd K (2000). Reported current use of prescription drugs and some of its determinants among 35 to 65 years old women in mid-Sweden: a population -based study. J Clin Epidemiol. 53; 637-43, doi: 10.1016/S0895-4356(99)00228-0.

8. Furu K, Straume B, Thelle DS (1997). Legal drug use in a general population: Association with gender, morbidity, health care utilization and lifestyle characteristics. J Clin Epidemil 50: 341-349, doi: 10.1016/S08954356(99)00362-9.

9. Bekke M, Hunskaar S, Straand J (2006). Self-reported drug utilization, health and lifestyle factors among 70-74 year old community dwelling individuals in Western Norway. The Hordaland Health Study (HUSK). BMC Public Health 6:121, doi: 10.1186/1471-2458-6-12

10. Ringbach Weitoft G, Rosen M, Ericsson O, Ljung R (2008). Education and drug use in Sweden-a nationwide register-based study. Pharmacoepidemiol Drug Saf 17:1020-1028, doi: 10.1002/pds.1635 
11. Nielsen M, Hansen EH, Rasmussen N (2003). Prescription and non-prescription medicine use in Denmark: association with socio-economic position. Eur J Clin Pharmacol 59: 677-684.

12. Fillenbaum G, Horner R, Hanlon J et al (1996). Factors predicting change in prescription and non-prescription drug use in a community residing black and white elderly population. J Clin Epidemiol 49: 587-593, doi: $10.1016 / \mathrm{S} 0895-4356(95) 00563-3$

13. Henricson K, Stenberg P, Rametsteiner G et al (1998). Socioeconomic factors, morbidity and drug utilization-an ecological study. Pharmacoepidemiol Drug Saf 7:261-67, doi: 10.1002/pds.364

14. Gundgaard J (2005). Income related inequality in prescription drugs in Denmark. Pharmacoepidemiol Drug Saf 14:307-317, doi: 10.1002/pds.1039.

15. Bjerrum L, Sogaard J, Hallas J, Kragstrup J (1998). Polypharmacy: correlation with sex, age and drug regimen. Eur J Clin Pharmacol 54:197-202.

16. Thomas HF, Sweetnam PM, Janchawee B, Luscombe DK (1999). Polypharmacy among older men in South Wales. Eur J Clin Pharmacol 55:411-15.

17. Haider SI, Johnell K, Thorslund M, Fastbom J (2008). Analysis of the association between polypharmacy and socioeconomic position among elderly aged $>$ or $=77$ years in Sweden. Clin Ther 30:419-27.

18. Haider SI, Johnell K, Weitoft GR et al (2009). The influence of educational level on polypharmacy and inappropriate drug use: a register-based study of more than 600.000 older people. J Am Geriatr Soc 57:62-9.

19. Junius-Walker U, Theile G, Hummers-Pradier E (2006). Prevalence and predictors of polypharmacy among older primary care patients in Germany. Fam Pract 24:14-19.

20. Little P, Dorward M, Warner G et al (2004). Importance of patients' pressure and perceived pressure and perceived medical need for investigations, referral, and prescribing in primary care: nested observational study. Br Med J 328:444-7.

21. Veehof LJ, Stewart RE, Meyboom-de Jong B, Haaijer-Ruskamp FM (1999). Adverse drug reactions and polypharmacy in the elderly in general population. Eur J Dlin Pharmacol 55:533-6. 
22. Alexopoulou A, Dourakis SP, Mantzoukis D et al (2008). Adverse drug reactions as a cause of hospital admissions: a 6-months experience in a single center in Greece. Eur J Intern Med 19:505-10.

23. Olivier P, Bertrand L, Tubery M et al (2009). Hospitalizations because of adverse drug reactions in elderly patients admitted through the emergency department: a prospective survey. Drugs Aging 26:475-82.

24. Veehof LJG, Stewart RE, Haaijer-Ruskamp FM, Meyboom-de Jong B (2000). The development of polypharmacy. A longitudinal study. Fam Pract 17:261-67.

25. Jyrrka J, Enlund H, Korhonen MJ et al (2009). Patterns of drug use and factors associated with polypharmacy and excessive polypharmacy in elderly persons: results of the Kuopio 75+ study: a cross-sectional analysis. Drugs Aging 26:493-503.

26. Antonakis N, Xylouri I, Alexandrakis $M$ et al (2005). Seeking prescribing patterns in rural Crete: a pharmacoepidemiological study from a primary care area. Rural Remote Health 6:488.

27. Tzimis L, Kafatos A (1998). Drug utilization and health behaviours among indigent elderly patients in Crete, Greece. Pharmacoepidemiol Drug Saf 8:105-14, doi: 10.1002/pds.398.

28. OECD Health Data 2009_Frequently Requested Data.

http://www.oecd.org/document/16/0,3343,em_2649_34631_2085200_1_1-1_37407,00.html ～(accessed 2 February 2010).

29. Yfantopoulos J (2008). Pharmaceutical pricing and reimbursement reforms in Greece. Eur J Health Econ 9:87-97.

30. Kontodimopoulos N, Pappa E, Niakas D, Tountas Y (2007). Validity of SF-12 summary scores in a Greek general population. Health Qual Life Outcome 5:55.

31. Pitsavos C, Panagiotakos DB, Chrysohoou C, Stefanadis C (2003). Epidemiology of cardiovascular risk factors in Greece: aims, design and baseline characteristics of the ATTICA study. BMC Public Health 3:32

32. Pappa E, Kontodimopoulos N, Papadopoulos A, Niakas D (2009). Assessing the socio-economic and demographic impact on health related quality of life: evidence from Greece. Int J Public Health 54:241-9.

33. Rosholm J, Christensen K (1997). Relationship between drug use and self-reported health in elderly Danes. Eur J Clin Pharmacol 53:179-183 
34. Bertoldi A, Barros A, Wagner A et al (2008). A descriptive review of the methodologies used in household surveys on medicine utilization. BMC Health Serv Res 8:222.

35. Van den Brandt PA, Petri H, Dorant E, Goldbohm RA, van de Crommert S (1991). Comparison of questionnaire information and pharmacy data on drug use. Pharm Weekbl Sci 13:91-6. 